\title{
Does IT Matter in Business Education? Interviews with Business School Deans ${ }^{*}$
}

\author{
Vasant Dhar, Arun Sundararajan \\ New York University, Leonard N. Stern School of Business \\ Working Paper \# CeDER-06-08, Center for Digital Economy Research
}

June 27, 2006

How are business schools thinking about developing leaders for the emerging digital economy? To answer this question, we interviewed 45 business school deans about whether knowledge about IT in business should be a part of core MBA education, and if so, how this knowledge should be delivered. A majority of deans recognize the importance of IT in business and the need for its presence in a forward looking core business curriculum that is training managers for an increasingly global and information rich future. There are three themes around which such a presence is described by them: understanding how the transformative and wealth generating potential of IT changes business and society, understanding how to make successful IT investment decisions, and facilitating innovation and creativity in the use of increasingly available data for decision making. However, a significant fraction of these deans struggle with the delivery of IT content in their core curriculum, and there is a clear divergence between the extent to which business school leadership considers IT in business important, and its realized presence in core MBA education. We identify the main reasons that contribute towards this divergence and how some schools are addressing it. Based on our findings, we outline the business importance and intellectual foundations for a natural question around which core education about IT in business can be structured, which asks "How does IT transform business and society?”

${ }^{*}$ We thank Steven Alter, Lynda Applegate, Adam Brandenburger, Kim Corfman, Vijay Gurbaxani, Lee Sproull, Bruce Weber and Peter Weill for feedback on earlier drafts, our faculty colleagues in the IS group at NYU's Stern School of Business for many insightful discussions, and participants at the 2005 Workshop on Information Systems and Economics and the 2006 HBS teaching workshop for their feedback. We also thank Wendy Fulenwider for her remarkable assistance. 


\section{Introduction.}

How should business schools educate managers for a global economy in which wealth creation is increasing mediated and governed by information technologies? Our conversations with the leadership of 45 business schools suggest that there is widespread recognition of the transformative role that IT has on business and society, and that there is great interest among deans of the top MBA programs in answering this question as part of education that is simultaneously forward-looking and grounded in concepts which emerge from theory. Our analysis identifies a core question that every business curriculum should address, and we outline the broad intellectual foundations that will enable future executives to think creatively about information technologies and their consequences.

In today's business world, information technologies are central to the development and delivery of a number of products and services, and often core to the product itself. They mediate an increasing fraction of the interaction among consumers, within firms, between firms and their customers, and, in contrast to physical built spaces, allow participants to continually and fluidly influence the design of these synthesized spaces. They increase the volume and accuracy of data generated by such interaction, the ability of firms to analyze these data, and their capability to respond creatively to signals they receive from markets and customers.

As a consequence of the centrality of IT in commerce and society, business models in industries that were stable over many decades now face persistent challenges for the foreseeable future. Success is governed increasingly by a firm's ability to respond to and influence the transformation induced by IT, rather than merely by the firm's operational or organizational excellence within the secure confines of a stable business model. Consider, for instance, those companies profiled in the bestselling business book "Built To Last", each of which outperformed the market in four successive decades, from the early 1950's to the early 1990's. Twelve of these 
eighteen companies have performed worse than the market over the last decade (Hamel, 2003). But this is not surprising when one recognizes that the industries many of them operate in financial services (Citigroup, American Express), corporate computing (IBM, HP), mobile handsets (Motorola), consumer electronics and music (Sony), entertainment (Walt Disney) and retailing (WalMart, Nordstrom) - are among those that IT has transformed radically over this decade.

Information technology is not just transformational but is also a central determinant of the successful business models and industry structure of a growing fraction of the economy. It has become the major driver of productivity growth, and there is evidence of significant variance in the performance of companies based on how effectively they use information technology (Brynjolfsson, 2003). As IT becomes cheaper and more ubiquitous, the opportunities for coinvention and devising organizational complements that realize the value of technological inventions grow steadily. There is constant and consistent trade press speculation about how a new information technology like RFID, WiMAX, or biometrics, or a new IT-enabled business or business model might transform an industry, or change the way we communicate, market, govern, and entertain. Expanding connectivity, mobility and digital convergence are powerful drivers that will only accelerate this trend. At the same time, there is considerable evidence that managers are increasingly concerned about not being able to make technology decisions rationally because of the complexity and far-reaching business consequences of such decisions, and also because of the need to invent business models and organizational strategies that take advantage of the growing centrality of IT in business.

How are business schools thinking about developing leaders for this type of emerging digital economy? How should they be training students to assess the threats to business models, and capitalize on opportunities enabled by emerging information technologies? Are there some general principles that can be applied to answer these questions? 
The Center for Digital Economy Research (CeDER) at New York University’s Stern School of Business has initiated a large-scale study that aims to deepen our understanding of effective education for a business environment in which IT is increasingly pivotal. In the phase of the study that we report here, we interviewed 45 business school deans about their views on whether knowledge about IT in business should be a part of core MBA education, and if so, how this knowledge should be delivered.

\section{Background and Motivation.}

An inquiry into core MBA education was initiated at NYU's Stern School of Business two years ago, following the school's philosophy that a core business course should be organized around a central question. The basis for this philosophy is that once this central question is defined, it provides coherence and stability to core education, since it keeps intellectual content relatively stable, while admitting examples and cases that vary with business context or the special interests and the competencies of the students and faculty. ${ }^{1}$ This is an especially appealing philosophy for teaching about IT in business, because the pace of technological change and the inherent subjectivity of assessing relevance make a course based solely on current IT cases and topics both unsatisfying and onerous to maintain.

This inquiry at Stern led to a proposal of the following initial core question for IT in business: Why do some organizations succeed with their information technology investments while others

\footnotetext{
${ }^{1}$ Consider, for example, what the core questions might be in Finance and Marketing. In Finance, it might be "how do you price assets and assess their risk?" As new asset classes emerge, new methods for pricing them are defined, but the question remains immutable. The marketing core question could be "how do you best acquire and retain customers?” Again, cases change as channels and consumer behaviors evolve but the question stays the same.
} 
do not? $?^{2}$ We convened a panel at the flagship annual Information Systems conference (the 2004 International Conference on Information Systems) to discuss whether there should be a core business question about IT in business, and if so, what it should be. The panelists represented the business schools at MIT, Michigan, Duke, NYU, Stanford, and the University of California, Irvine. The importance of a core question was widely acknowledged by the panel and its audience. More importantly, a basic recognition that emerged was that as information technologies have matured and their importance to business become more central, newer central questions emerged. Information technology shifted from a support role to one where it was an inherent part of a firm's value proposition. The late Gerry DeSanctis proposed that over time, the following questions have been central to IT in business:

1970s: How do organizations design, program, and operate their information systems?

1980s: How can systems be designed to be user friendly and accepted by the organization?

early 1990s: How can organizations exploit IT for strategic advantage?

late 1990s: How can ecommerce be creatively used for organizational success?

2004: Why do some organizations succeed with their IT investments while others do not?

Old questions don't die out, they become less important as their solutions become commoditized, and new ones are added as the discipline moves forward. Further, many disciplines chase common questions. For example, today there is interest in the following topics across disciplines: globalization, networks, security, ethics, entrepreneurship, cross-cultural differences, and managing knowledge. New topics will be on the horizon tomorrow. It is neither necessary nor

\footnotetext{
${ }^{2}$ Shorter though less precise formulations, might be "How do you make your IT investments successful?” or “What makes an organization's IT investments successful?”
} 
appropriate to build walls between disciplines or MBA core course boundaries. Timeliness of pedagogy requires that students study some questions from multiple vantage points. Indeed, one could expect that such an approach would also promote "out of the box" thinking that would be useful to future business leaders.

The panel also acknowledged that as a practice-oriented degree, the content of an MBA course should be both (a) fundamental (things that do not change much over time) and (b) timely (address current challenges and trends). Some of the panelists felt that the proposed NYU question was indeed timely. The majority of the panel felt that the question was fundamental and appropriate to business but there was less agreement on whether it is general enough. The panel suggested that each school might be better off choosing some flavor or variant of this question depending on the size and diversity of their faculty. A transcript of this panel is available on request.

There was also some debate about whether the core question is best addressed by a course whose focus would be on information technologies in business or whether it could be infused into other courses. For example, the question as stated could in principle be addressed in a strategy course (how to link IT with corporate strategy; how IT changes business models and the basis for competition), a marketing course (study of electronic commerce and how organizations effectively employ ecommerce solutions to attract and retain customers), and (to some extent) a finance course (valuation of IT assets and ROI or other methods for assessing investment payoffs from information technologies).

\section{Our Interviews with Deans.}

It became apparent after the panel that many of the open questions that were discussed and debated during the panel's session seemed better addressed to deans of business schools, whose 


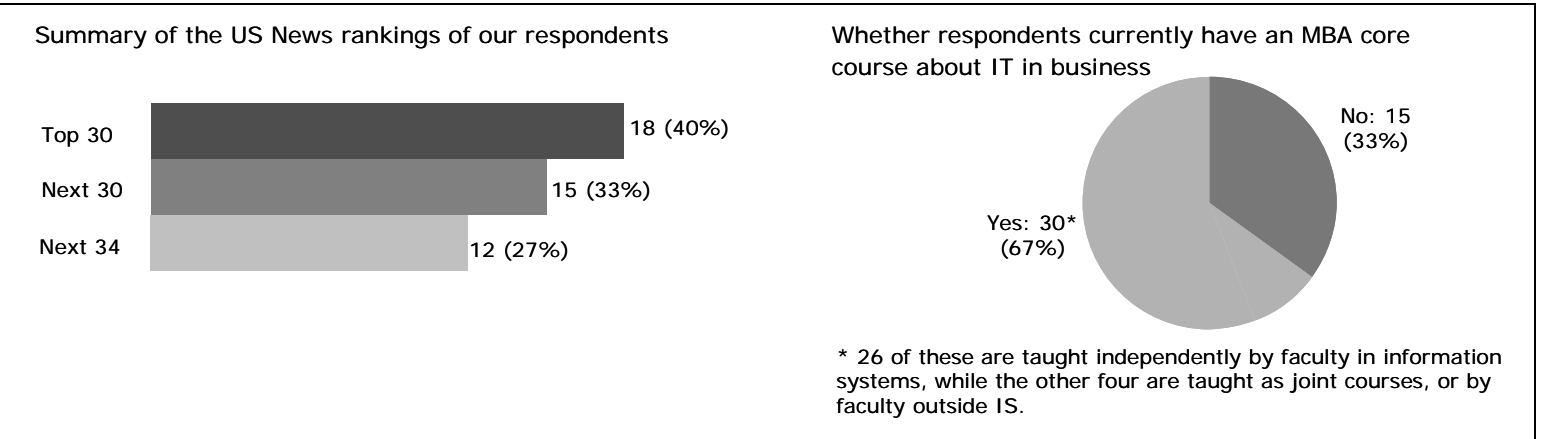

Figure 1: “Demographics” of our respondents.

broader perspective and impact on business education might provide a more realistic basis for moving forward. In July 2005, we contacted each dean of the top 94 U.S. business schools by sending them a letter inviting them to share their perspective on IT in business education. We compiled this list by combining the 88 schools listed in the 2005 U.S. News and World Report annual ranking of full-time MBA programs with the 78 U.S. schools listed in the 2004-05 BusinessWeek ranking of full-time MBA programs. The letter asked for their views on the following two questions:

(1) Do you think that teaching MBA students about IT in business (as stated in the NYU question or as a variant of this question) is important?

2) If so, what do you believe is the most effective way of delivering this knowledge?
a) As an independent core course
b) As a required "choose one from many variants" course
c) As content integrated into one or more other MBA core courses
d) In some other way

Following this mailing, each Dean's office was contacted via telephone to set up an interview. Forty five business school deans responded. Figure 1 shows the demographics of the respondents and whether they have a dedicated core about IT in their curriculum. Two of these responses were 
1. Do you think that teaching MBA students about IT in business (as stated in the NYU question or as a variant of this question) is important?

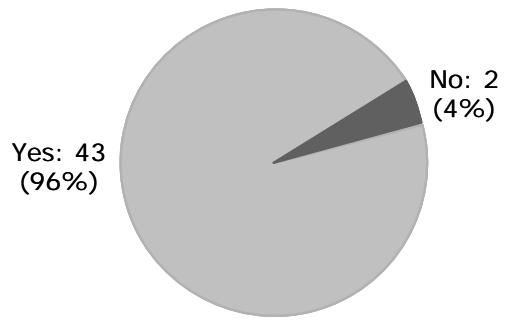

2. If so, what do you believe is the most effective way of delivering this knowledge?

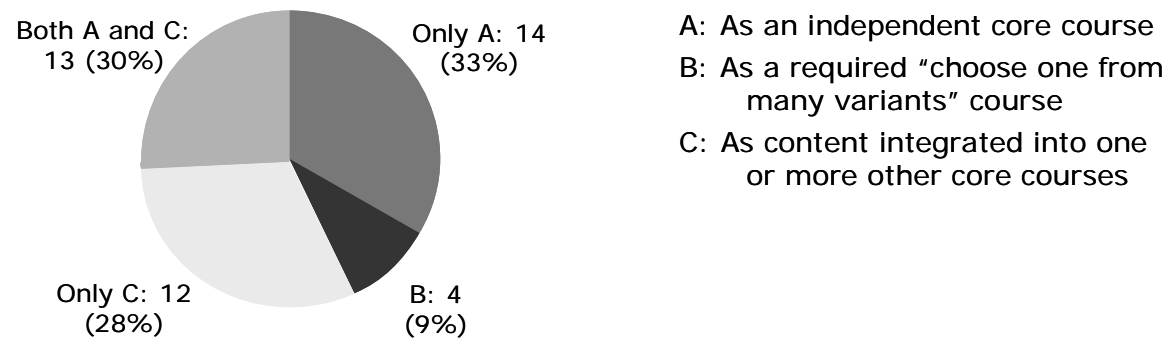

Figure 2: Summary of responses to two questions

via email. We interviewed the other forty-three (over the telephone, for all but one, which was face-to-face). The typical duration of these interviews was 30 to 45 minutes (although many lasted over an hour), leading to context and color well beyond our two questions. Thirty three deans participated in these interviews personally, six delegated it to an associate dean, and four delegated it to professors whose responses they maintained reflected the Dean’s position.

So, what did the deans say? Without exception, they were deeply engaged by the conversation and acknowledged the timeliness of this study. Almost with exception, deans (43 out of 45) were affirmative in their answer to the question "Do you think that teaching MBA students about IT in business (as stated in the NYU question above or as a variant of this question) is important?” While interviewing each respondent, we discussed, at some length, the basis for their position ${ }^{3}$.

\footnotetext{
${ }^{3}$ Of the two respondents who answered "No" to question 1, one indicated a position that IT is important as a facilitator to learning, but not as content in a business curriculum. The other
} 
One or more of the following three sets of reasons summarizes why business school deans believe that learning about IT in business is important to future business executives. (The italicized phrases highlight the key parts of each point.)

1) Information technologies continually transform business and society. They are a central driver of accelerated globalization. They cause increasingly frequent changes in the structure of industries and the successful business models within them. A large fraction of future wealth creation will be due to progress in technology (and especially information technologies). Successful executives in the future will have a clear understanding of how to take advantage of this transformative and wealth generating potential of information technologies. Roughly half the deans indicated this transformational perspective as the basis for core IT in business education.

(2) Investments in IT are critical to the success of organizations. Successful managers will therefore be able to assess and invest in the IT that best supports their business model. They will be able to determine the optimal level of investment in these technologies. They will know how to appropriately measure the return on these investments. They will be equipped to identify the right inputs into models that form the basis for such analysis. About a quarter of the respondents fell into this category.

(3) Success as a business executive depends critically on innovation and creativity in the use and application of data for decision making. A growing fraction of these data are generated and available as a by-product of electronic commerce. Information technology defines the data blueprint of an organization. Data are key to knowledgeable and effective decision-making. Roughly a quarter of the deans had this decision-making oriented view of IT.

maintained that while learning about IT in business is certainly important, it is not core to a curriculum that emphasizes rigorous concepts that will be invariant over time. 
An informal "show of hands" poll that we conducted during an IS faculty teaching workshop held at Harvard Business School in May 2006 suggested that the three reasons are in fact central themes of courses currently taught by many IS faculty. Although some schools indicated covering more than one of these themes in their core courses, the "transformation" theme embodied in (1) is the most popular. For example, one of the variants of the core MBA course in IS at Stanford University taught by Haim Mendelson ${ }^{4}$ seems to be structured around the idea that IT transforms business, addressing both industry transformation and process transformation. Many other leading business schools, including those at NYU, Berkeley, CMU and UC Irvine have adapted cases and material from this course into their curriculum. A capstone course titled "Digital Transformation” under development at CMU's Heinz School of Public Policy will teach its students about how IT transforms both business and society.

Responses to our second question "What do you believe is the most effective way of delivering this knowledge," were quite varied. A majority, 27 out of 43, believe that a core MBA curriculum should have an independent course about IT in business. Many of these base their position simply on the assertion that IT in business is important enough for it to have an independent presence in an MBA core. Others in this group believe that an emphasis on integrating IT (or for that matter, other potentially integrative topics like ethics and globalization) into core courses would distract from the teaching of their core ideas, and thus, an independent core course is the pedagogically superior choice. A few of the deans in this group feel that integrating IT into other core courses, while pedagogically ideal, it not feasible because of limitations they perceive in their faculty's expertise, the difficulty in designing interdisciplinary content in schools whose organization and reward structure is discipline-based, and the negative impact that multi-instructor courses can have on a student's learning experience. Three of them

\footnotetext{
${ }^{4}$ OIT356 Electronic Business and Commerce. As of June 2006, an outline of this course was available at http://faculty-gsb.stanford.edu/mendelson_EBC/
} 
suggested that a core course about IT in business might be one of a menu of "optional" core courses.

Almost a third (13 out of 43) of the deans believe that a core MBA curriculum should integrate an understanding of the importance of IT in business across its courses, as well as including an independent core course dedicated to the subject. This is based on a perception that IT is so central to business that a core curriculum should first include learning of the basic corpus of knowledge about IT in business independently, and subsequently connect this learning and its application with concepts from other core areas of business such as corporate finance, marketing and strategy.

Further, 12 out of 43 deans believe that content relating to IT in business should be exclusively integrated into courses that teach material core to other business disciplines. Strategy, corporate finance, economics and supply-chain management/service operations were among those suggested. The common rationale for integration was a belief that teaching about IT is best done in the context in which the technology is used. Some deans also indicate a divergence between the expertise of their IS faculty, and the body of knowledge they believe is core to IT in business, which has led to their concluding that integration is a better path towards delivering on the latter. This is the model at Duke and Dartmouth primarily due to their small faculty size.

A small group of respondents (4 out of 43) advocate requiring a course about IT in business, but allowing students to choose this from one of 2 or 3 alternative IT courses. This is the current model at Stanford. Their basis for this position is that MBA students have varied technology backgrounds, and that different career paths require different learning about IT in business. The latter might also be said about a number of other business courses that feature in the MBA core, and this is a position with which two deans from this group of respondents concurred. 


\section{Issues Beyond Our Questions.}

The interview format of our conversations encouraged the deans to express their views on issues beyond the two questions, several of which are worth mentioning. The first is the weight of history and politics on what is considered "core" business knowledge. There is considerable variance in what the deans consider core, although accounting and statistics seem to be universally regarded as essential. Considering this variance, it is not surprising that decisions about what is core to MBA education have been driven by taste, politics, and pragmatics. A few schools have gravitated towards a one semester core, most notably MIT, which teaches accounting, data and decision making, microeconomics, management communication, and organizational processes. This mix, a committee decision, is, as at most schools, the result of many hours of deliberation and compromise.

A corollary to the above finding is that there is often a divergence between the desires or views of the deans and the actualization of these desires in the curriculum, because of inertia, politics, or the fact that the silo effect of departments and the incentive structures of large research universities don’t encourage integrative teaching. Many of the deans considered information technology issues in business to be the integrative ones, and therefore the ones that are much harder to staff if interdepartmental silos are deep ${ }^{5}$. While over $90 \%$ of the deans of schools we interviewed believe that education about IT in business should be part of their core curriculum,

\footnotetext{
${ }^{5}$ Many deans also drew the analogy between information technology and "global" and "ethics" topics, owing to their similarity as current and potentially integrative issues that are not widely present in the core. A common question was whether all three of these should permeate core courses, considering the importance of globalization and information technology, and the recent emphasis on ethical and sound corporate governance.
} 
just over half of their schools have such a presence. Any realistic path towards bridging this gap in core business education needs to recognize and address the drivers of this divergence.

While acknowledging its importance, only a small fraction of business school deans currently view their capability to educate executives about IT in business as a key differentiator. An example is Howard Frank, dean of the business school at the University of Maryland, who sees the economy of the world being transformed radically by IT and biotechnology. As a business transforming technology, IT needs to permeate the curriculum, notes Frank, who has positioned his school as training leaders for the digital economy. Similarly, the business school at UC Irvine identifies three drivers of sustainable and profitable growth for business - strategic innovation, information technology and analytical decision making - and structures its core curriculum around these drivers.

The deans of this "IT as a differentiator" group advocated both an independent core course as well as integration of IT-related ideas into other core courses, and believe strongly in the transformational power of IT. While two of the schools in this group now have IS/IT departments ranked as "top-5" in different surveys, this ascent followed the choice of positioning by their deans, rather than leading it. In contrast, this group did not include IS departments that have consistently ranked highly over the last ten years. This suggests that a position of leadership in education about IT in business is driven from the top, rather than emerging from within, a trend we expect will sustain at least in the near future. The corporate analogy - that success with one's IT investments is often determined by strong senior executive support - seems to apply to business schools as well.

\section{Two Central Themes: Flexibility and Conceptual Invariance.}

The final two themes that emerged are probably the most relevant towards moving ahead and thinking about how information technology fits into the business curriculum. The first is a trend, 
in the leading business schools, towards greater curricular flexibility, a smaller set of required and core courses, and a belief that giving students the ability to customize their own curriculum can result in more effective learning. Seven of the schools in the top-30 advocated one of two varieties of flexibility in their school's approach to core education about IT in business - a menu of IT in business courses from which students choose one, or an IT in business course as part of a menu of core courses. This flexibility places the onus of being forward looking on the shoulders of the students and also gives business school leadership more latitude in shaping the composition of the menu of required courses, thus enabling them to signal to students what the school considers core to business education.

Stanford's business school is about to undergo a radical change towards greater flexibility, or viewed more radically, towards “mass customization.” In June 2006 they announced a new MBA curriculum, to be implemented in the fall of 2007, that will match each student with a menu of course options based on that student's past education, work history, and goals. Each student will also sign up for a global experience, like an internship overseas or an exchange program with an overseas university. This decision was based on feedback from hundreds of students and alumni. According to BusinessWeek, Garth Saloner, the professor who headed the task force that developed the new program said that "the one-size-fits-all curriculum wasn't working." The new approach, he says, is "part of the maturation of the MBA." (Gloecker, 2006).

In addition to flexibility, a pedagogical theme that characterizes the thinking of many deans of top-30 business schools is structuring a core curriculum that is simultaneously based on fundamental concepts, and that is forward looking. For example, the dean of the Stern School of Business at NYU, Tom Cooley, describes the goal of a business school as

"Providing a meaningful and serious intellectual experience, one that prepares students to be leaders in a complex evolving world...the mission is to understand 
markets, firms, and prices as well as to develop new strategies and discourses for understanding how they work, how they interact, how they impact society.” (Cooley, 2005).

One of Cooley's points is that when preparing students for a career that will span multiple decades, general theories will have more enduring value than facts and context that describe the current business environment. Richard Schmalensee from MIT’s Sloan School and Edward Snyder from the University of Chicago echo a similar sentiment, highlighting a belief in teaching concepts that remain stable within an evolving business context. Examples of such concepts include those embodied in the economics of markets, statistical analysis, human decision making and problem solving. At the same time, Cooley, Schmalensee and Paul Danos of the Tuck School at Dartmouth speak about the importance of being forward looking. Considering the extent to which information technologies will be a part of the wealth creation process going forward, they say, it is important that students understand how to think about these technologies and their consequences.

While it is important to structure a core course around a fundamental question, recall that our original panel recognized that with information technologies, fundamental questions get added over time. The core question in the 1970s asked how to operate and manage systems. This question is still relevant for every business, but it has been commoditized, and isn't central to business education anymore. Over time, others have arisen and assumed more importance. Accordingly, we also discussed with the deans whether an increase in the pace of business transformation might alter the set of fundamental concepts that are relevant to core business education over time. For example, the basic models of inventory management, a staple in most core MBA operations courses, have not changed over the last decades. However, as noted by the dean of the Wharton School, Patrick Harker, the fraction of GDP generated by the service economy has increased dramatically over time, and the important operations problems most 
executives need to be familiar with have to do more with managing services, rather than with the procurement of physical inputs. Rather than being an isolated example, this highlights the challenge of balancing the desire for "stable" concepts with the need to be relevant and forward looking. The fundamental concepts central to long-term business success do evolve, informed by a vibrant culture of research in business schools. We are currently still early in the process of IT transforming business.

\section{IT in Business Education: Looking Forward.}

So, how should business schools be thinking about information technologies in a way that is both relevant and theoretical? Based on the last forty years of the history of information technology in business, for example, are there some "invariant" concepts upon which thinking about future business models and industry structure can be based, and which provide relevant inputs into financial, marketing, or production models?

There are. If we consider the history of IT over the last forty years, three indisputable technological invariants emerge. The first is the rendering of things as information, and in particular, as digitally represented information. A bank balance is information about wealth, occasionally rendered into physical money. Music, voice and video are information about frequency, pitch and color, and the rate at which these change. A trading strategy is a set of rules (code) that act on information. Each of these kinds of information can be digitized. Once digitized, this information is amenable to a variety of forms of computation and transport.

The second invariant is the sustained exponential growth of hardware power, bandwidth, storage, and the accompanying miniaturization of IT-based devices. Moore's law is an empirical rendition of this phenomenon. As the power of IT crosses various thresholds, the capabilities it enables causes disruptive shifts in markets and society. Massive parallelization and the move of 
functionality to software, as epitomized by Google’s current approach to radically more effective large-scale computing using mass-market hardware, is accelerating this trend.

The final invariant is the most subtle. It is the sustained increase in programmability, in a modular way, whereby increased complexity can be aggregated, codified and eventually integrated into standardized software platforms. In the 1960’s, Herbert Simon had characterized decision making on a continuum of programmability, predicting that computers would replace programmable organizational functions, leaving humans to handle the non-programmable tasks. Simon's predictions were somewhat aggressive but have indeed materialized, with information processing infrastructures of increasing complexity becoming programmed and available as modules that handle entire processes from order taking to fulfillment, inventory management, and customer support. Modularity is fundamental to why IT has an increasingly powerful transformative effect on business and society. The addition and improvement of modular layers can enable capabilities and business models that wouldn’t exist otherwise.

Why are the three invariants relevant to business education? When combined, they lead to at least four consequences of substantive and lasting future importance.

First, digitization in conjunction with the growth in processing power facilitates the separation of information from a growing number of artifacts. Digitization makes this separation feasible. The exponential growth in the power of hardware and network bandwidth makes it viable and practical. For example, the capability to digitize music existed for a long time before the commercial digitization of music, which occurred only when there was a high-capacity storage medium inexpensive enough to hold the hundreds of megabits that comprise a three-minute song, and a special-purpose mass-market hardware device, the CD player, powerful enough to render these millions of bits in real time. Even so, music remained tied to a tangible artifact, the CD. The separation of the digital information contained in a song from this artifact became useful only 
when there was sufficient bandwidth to easily send and receive these millions of bits, and when enough consumers owned sufficiently powerful general-purpose computers which could run the software capable of such rendering. The digitization of voice telephony and video has occurred on the "backbone", and the separation of digital video from its artifact, the DVD, is imminent. Most money has been separated from its operational artifact, the bank note. The separation of information from its artifacts alters the fundamental economics of a number of industries. Their products become information goods, often subject to network economics. Music, film and publishing are early examples; there will be more. Recall that music was not considered in any way to be part of the IT industry twenty years ago.

Second, IT “infrastructures” become progressively larger, more powerful, and more accessible. They become more powerful because hardware is faster, software can be layered in a modular fashion, and their combined capability made more accessible as network bandwidth continues to grow. This trend has characterized the IT industry over the last fifty years, from the emergence of standard commercial computers in the 1950's and 1960's, the creation of the first standardized platform, the IBM System/360, through the recent availability of billion-dollar off-the-shelf enterprise resource planning and supply-chain management software platforms, and to the ondemand retailing and search platforms of Amazon.com and Google.

The interpretation of the recent visibility of powerful and shared infrastructures as evidence that IT is being "commoditized”, and thus not of consequence to business professionals (Carr, 2003) is flawed and misses a fundamental point. Yes, the ability to develop and manage generic complex IT infrastructures of specific kinds is a less valuable business capability. But this has always been the case. Each of the developments that "commoditizes" some aspect of IT infrastructure, while reducing the return or advantage that accrued from the capability to build or manage such infrastructure, is also accompanied by an increase in the relevance and impact that 
IT has on business. ${ }^{6}$ As noted by Vijay Gurbaxani, this leads to an increase in the total business spending on IT (Gurbaxani, 2003), and often, a dramatic shift in the business models and structure of industries that were once not considered part of the "IT industry". What is important is what these large shared infrastructures enable, and the extent of change they engender.

Here are two simple illustrations of the power of shared infrastructures. A brokerage house interested in analyzing the impact of business news on stock prices need not build a system that gathers them from disparate web-based new sources, or contract with a dedicated news provider like Lexis/Nexis, but can simply use Google News, a publicly available shared infrastructure made possible by Google’s ability to dynamically assess the importance of news as it happens. The emergence of radio frequency identification (RFID), a technology that enables physical objects to "talk to each other," coupled with the transmission structure of the Internet enables the implementation of location-specific advertising and selling strategies in physical space that were previously possible only if products were in a digital shopping cart. Clearly, unless one understands what current and emerging infrastructures of this kind enable, it is hard to appreciate and foresee how the business models in one's industry will shift in the future.

The third major consequence of the three invariants is a growth in the importance and variety of "spaces of interaction” in society that are mediated by IT. The fundamental difference between

\footnotetext{
${ }^{6}$ More specifically, the emergence of commercially available computers in the 1950's and 1960's increased their use in business and research (although reducing the value of being able to build one). The availability of the IBM System/360 with a standardized operating system facilitated this further (but reduced the value of being able to develop and deploy customized business applications). The availability of off-the-shelf enterprise resource planning and supply-chain management software lets more firms use them to manage their operations (although managing the building of customized firm-wide information systems becomes a less critical capability for modern managers). A potential online vendor can now simply “plug into” Amazon.com’s retailing platform in exchange for a per-transaction fee (rather than needing to build electronic shopping systems from scratch).
} 
these synthesized spaces which foster computer-mediated communication and the "built spaces" that govern behavior in the physical world is that the former are shaped continuously and fluidly by the participants who occupy them. More powerful infrastructure allows participants to support the complex interfaces of these spaces; software layering enables these spaces to evolve, and lets participants build new ones with little effort. Progress in hardware facilitates mobility in the device that renders this space. The digitization of everything facilitates exchange mediated by these spaces: devices can organize and manipulate information in a way not previously possible, giving rise to new social structures and business models, and disrupting existing ones. Contrast this with the pace of change in telephonic or face-to-face communication that analog networks or physical built spaces mediate.

The final consequence of the invariants is the availability of data about interactions that are increasingly mediated by these new "spaces," and the ability to process these data faster and more intelligently. The more electronic the spaces of interaction between agents, and the more this interaction involves the transaction of digital goods, the richer the data trails created, and the greater the possibility of their intelligent interpretation and summarization in real time. What is knowable about individuals, business, and society increases tremendously as such data become available. It also elevates to the boardroom, issues of data governance, privacy, security, and the risks to business and governments that result from alternative policies and processes.

These consequences suggest a future for business that is inextricably intertwined with information technology. We started by asking whether there is a core question that can usefully ground education in this area. The question asking why some organizations succeed with their IT investments while others don’t is a useful one, but probably not general enough. Perhaps a more general question, one that will remain central for the foreseeable future is "How do information technologies transform business and society?” Certainly, our three invariants form a basis for educating business leaders how to think about IT and its consequences for business and society. 
Such learning will undoubtedly lead to further consequences of importance, perhaps identified by those executives who are trained appropriately for a digital business future. As Louis Latiaf [2005], the dean of Boston University's school of management notes in a recent article, “Tomorrow's leaders need to understand technology in the same way as todays understand accounting and finance”.

The four consequences of the technological invariants on business and society are already the subject of a substantial tradition of research, within business schools and beyond, which creates the intellectual foundations for education about IT in business. A growing body of knowledge about the economics of information technology and technology strategy informs teaching about industries being digitized, or being transformed by shared IT infrastructures. Research into the sociology of computer-mediated communication, on the nature of technology adoption, and on its acceptance within socially constructed institutions tells us what to expect as synthesized spaces become more ubiquitous. Research in machine learning and knowledge discovery from data gives us the ability to frame, in a rigorous way, how to think about analyzing large business data sets. These are active and rapidly growing research areas within business schools. Each research tradition is at least twenty years old, and still vibrant. Further, there is an increase in the presence and importance of IT-centric business school research which studies the transformational aspects that IT has on business and society (Agarwal and Lucas, 2005).

How these invariants and their consequences are discussed will be shaped by the strengths and tastes of each business school. It seems clear, however, that any forward looking business school must address them as part of its curriculum. There are different ways of doing this. One way is to dedicate a core course to IT in business, one that focuses on answering a fundamental question of how information technologies change business and society, perhaps as part of a menu. Another approach is to infuse such a question into other courses, although most deans expressed skepticism with the workability of this approach. From a longer-term and more strategic 
standpoint, business school leadership may find it rewarding to increase funding and support for integrative curricular design and research that is related to IT in business, and manage the composition of their faculty to deliver on such innovation. The extent to which this is done may be a central driver of the sustained relevance and success of business education as we currently practice it.

\section{References}

1. Agarwal, Ritu and Henry Lucas, 2005. The Information Systems Identity Crisis: Focusing on High-Visibility and High-Impact Research. MIS Quarterly 29 (3).

2. Applegate, Lynda, Robert Austin and Warren McFarlan, 2005. Corporate Information Strategy and Management 7/e. McGraw Hill Irwin.

3. Brynjolfsson, Erik, 2003. The IT Productivity GAP. Optimize, June.

4. Carr, Nicholas, 2003. IT doesn’t matter. Harvard Business Review, May.

5. Cooley, Thomas, 2005. Business Education for the Future. Mimeo, New York University.

6. Gloeckler, Geoff, 2006. Where No Two MBA’s Are Alike. BusinessWeek June $19^{\text {th }}$

7. Gurbaxani, Vijay, 2003, in Does IT Matter? An HBR Debate. Harvard Business Review, June

8. Hamel, Gary, 2003. The Quest for Resilience. Harvard Business Review, September.

9. Lataif, Louis, 2005. The next generation of MBA’s. Financial Times, November $14^{\text {th }}$.

10. Lessig, Lawrence, 2000. Code and Other Laws of Cyberspace. Basic Books. 